Results 480 biomarker assays were performed in 80 samples from ten infants. OI correlated positively with BNP, NTproBNP, and VEGF-A, and negatively with PLGF (Table 1). PH measures correlated negatively with PLGF and positively with NTproBNP and Troponin1. Measures of diastolic function correlated negatively with Troponin 1 and VEGF-A, and positively with PLGF.

Conclusions 1) Plasma biomarker analysis is feasible in infants with $\mathrm{PH}$ in $\mathrm{CDH}$.

2) Worsening disease status (impaired oxygenation, PH, diastolic dysfunction) was associated with elevated BNP, NTproBNP, Troponin 1 and VEGF-A, and reduced PLGF.

3) The utility of these peptides as disease biomarkers, prognostic indicators, and their role in disease pathogenesis merits further investigation.

\section{0-024 OUTCOME RESEARCH IN 77 PATIENTS WITH PULMONARY ARTERIAL HYPERTENSION RECEIVING SILDENAFIL: A DOUBLE-BLIND, RANDOMISED CONTROLLED STUDY}

II Palii, ${ }^{2} E$ Vataman, ${ }^{3} \mathrm{~N}$ Revenco, ${ }^{4} \mathrm{~L}$ Maniuc, ${ }^{5} \mathrm{M}$ Vataman, ${ }^{4} \mathrm{O}$ Repin. ${ }^{1}$ Paediatric Cardiology, Institute of Mother and Child, Chisinau, Moldova; ' Laboratory of Heart Failure, Institute of Cardiology, Chisinau, Moldova; ${ }^{3}$ Department of Paediatric SUMF, SUMF Nicolae Testemitanu, Chisinau, Moldova; ${ }^{4}$ Congenital Heart Diseases, Cardiac Surgery Centre, Chisinau, Moldova; ${ }^{5}$ Department of Echocardiography, Diagnostic German Centre, Chisinau, Moldova

\subsection{6/archdischild-2014-307384.93}

Purpose PAH resulting from CHD - a major cause of postoperative morbidity and death. Sildenafil: selective inhibitor of phosphodiesterase-5 - an effective and promising pulmonary vasodilator, with minors reverse effects.

Methods This monocentric, randomised placebo-controlled study evaluated the efficacy, safety, tolerability of oral Sildenafil in children with severe PAH secondary congenital shunts (simple (14 patients), mixed (35), complex (28)). $77 \mathrm{PAH}$ patients (35 - repaired shunts, 31 - palliative, 11 inoperable) assigned to placebo or Sildenafil - dose of $1-2 \mathrm{mg} / \mathrm{kg} / \mathrm{day}$ each $8 \mathrm{~h}$ : 6-12 months. Sildenafil group - 38 (mean age 19, $9 \pm 5$, 3 months: 16 boys/22 girls); placebo -39 (mean age $21,7 \pm 7$, 8 months: 22 boys/17 girls). Research protocol: FC NYHA; 6-min walk test; O2 saturation; echocardiography PAPm, myocardial performance index (MPI/Tei index), right cardiac catheterisation - PVRI; questionnaire for adverse reactions was available.

Results Sildenafil patients improved FC from 3,16 $\pm 0,1-2$, $15 \pm 0,1(\mathrm{p}<0,001)$; effort tolerance $(+152,5 \pm 17,4 \mathrm{~m}-6$ months and $+184,3 \pm 21,2 \mathrm{~m}-12$ months of treatment), $(\mathrm{p}<$ $0,001) ; \mathrm{O}_{2}$ saturation $(+3,1 \pm 0,5 \%)$ but placebo $(+0,6 \pm$ $0,3 \%)$, ( $<<0,001)$; PAPm decreased: $22,0 \pm 2,22$ at 6 months with 19,03 $\pm 2,3 \mathrm{mmHg}-12$ months ( $<<0,001$ ); PVRI decreased: $2,45 \pm 0,19 \mathrm{UWood} \cdot \mathrm{m}^{2}(\mathrm{p}<0,001)$; Tei index with $0,15 \pm 0,01(-31 \%)$ to initial $(\mathrm{p}<0,001)$. In placebo group only PVRI diminished from $6,4 \pm 0,1$ to $5,7 \pm 0,3 \mathrm{UW} / \mathrm{m}^{2}$ (p < $0,05)$. No death in the Sildenafil group, but 5 in placebo.

Conclusions Sildenafil - efficient in treating severe $\mathrm{PAH}$ secondary to congenital shunts, but even more effective in children after cardiac surgery. Sildenafil improves FC, effort tolerability, $\mathrm{O}_{2}$ saturation, $\mathrm{RV}$ global function, diminishing PAPm and PVRI comparing with placebo. Sildenafil has good safety, tolerability, favourable impact on life quality - insignificant adverse reactions.

\section{Cerebral Oxygenation}

\section{0-025 DO SUSTAINED LUNG INFLATIONS DURING RESUSCITATION OF PRETERM INFANTS AFFECT CEREBRAL BLOOD VOLUME AND CEREBRAL REGIONAL OXYGEN SATURATION?}

B Schwaberger, G Pichler, C Binder, N Baik, B Urlesberger. Division of Neonatology, Medical University of Graz, Graz, Austria

\subsection{6/archdischild-2014-307384.94}

Background and aim Sustained lung inflations (SLI) promote lung aeration and alveolar recruitment.

Changes in total haemoglobin $(\Delta \mathrm{cHb})$ and cerebral tissue oxygenation index (cTOI) measured by near-infrared spectroscopy (NIRS) give information on changes in cerebral blood volume (CBV) and regional oxygen saturation, respectively.

Do SLI during resuscitation affect CBV and cTOI?

Methods Preterm infants $\geq 28+0$ and $<34+0$ gestational weeks and need for respiratory support (RS) during postnatal transition were included. Within the first $15 \mathrm{~min}$ of life of each subject $\Delta \mathrm{cHb}$ and cTOI were continuously detected by using 'NIRO200-NX’ (Hamamatsu; Japan).

Two groups were compared based on RS:

SLI group: RS was started by applying 1-2 SLI for $15 \mathrm{sec}$ at 25 $\mathrm{cmH} 2 \mathrm{O}$ and continued by continuous positive airway pressure (CPAP) or positive pressure ventilation (PPV).

Control group: CPAP/PPV depending on respiratory insufficiency. Results 40 preterm infants (23 female) with mean gestational age of $32+1$ weeks ( \pm 3 days) and mean birth weight of $1707 \mathrm{~g}$ $( \pm 470)$ were included. Demographic data did not show significant differences between groups.

Median $\Delta c H b$ was in SLI/control group $-0.38 / 0.20 \mu \mathrm{M} 30$ sec after initializing RS, $-1.33 /-0.43 \mu \mathrm{M}$ after $60 \mathrm{sec}, 3.37 / 2.30$ $\mu \mathrm{M}$ after $2 \mathrm{~min},-0.19 /-0.46 \mu \mathrm{M}$ after $3 \mathrm{~min}, 2.52 / 1.05 \mu \mathrm{M}$ after $5 \mathrm{~min}$ and $2.93 /-4.78 \mu \mathrm{M}$ after $10 \mathrm{~min}$.

Median cTOI increased in SLI/control group from 49/47\% 30 sec after initialising RS to $54 / 50 \%$ after $60 \mathrm{sec}$, to $56 / 51 \%$ after $2 \mathrm{~min}$, to $56 / 58 \%$ after $3 \mathrm{~min}$, to $61 / 61 \%$ after $5 \mathrm{~min}$, and to $65 / 69 \%$ after $10 \mathrm{~min}$.

Conclusion Initialising RS immediately after birth by using SLI in preterm infants did not show significant differences in CBV and cTOI compared to control group.

\section{0-026 INFLUENCE OF PATENT FORAMEN OVALE (PFO) ON REGIONAL CEREBRAL OXYGEN SATURATION DURING IMMEDIATE NEONATAL TRANSITION}

N Baik, B Urlesberger, T Freidl, B Schwaberger, C Binder, G Pichler. Neonatology, Medical University Graz, Graz, Austria

\subsection{6/archdischild-2014-307384.95}

Background During postnatal transition there is a significant association between regional cerebral oxygen saturation of the brain and the shunt via the ductus arteriosus (DA). The influence of the patent foramen ovale (PFO) on the cerebral regional saturation remains as a question.

Aim The aim of the study was to investigate the influence of the PFO on the cerebral oxygen saturation, measured by near-infrared spectroscopy (NIRS) after 15 min of neonatal transition.

Methods Observational study. Term neonates ( $>37$ weeks of gestational age) after elective caesarian section and without any 